\title{
Realidades del conflicto armado en los contextos actuales de las infancias: aportes para edificar paz desde el aula de clase
}

\author{
Riquelio Vargas Suarez \\ riquelio.vargas@unad.edu.co \\ Universidad Nacional Abierta y a Distancia UNAD \\ Pitalito, Huila- Colombia \\ Gisela Beatriz Gallego Ruíz \\ gisela.gallego@unad.edu.co \\ Universidad Nacional Abierta y a Distancia UNAD \\ Florencia, Caquetá - Colombia \\ Blanca Nery Serna Agudelo \\ b.serna@udla.edu.co \\ Universidad de la Amazonía \\ Florencia, Caquetá - Colombia
}

\section{RESUMEN}

El presente artículo tuvo como objetivo caracterizar las realidades del conflicto armado que han vivido los niños en el departamento del Caquetá- Colombia. Este estudio se fundamentó desde los aportes de la investigación descriptiva con un enfoque cualitativito. Los principales hallazgos están relacionados con la implementación de entrevistas, guías de observación y diarios de campo. Los resultados se consolidaron a través de tres fases: caracterización, intervención y evaluación, tomando como categorías de análisis el componente social, cultural, psicosocial, cognitivo y económico. La población estuvo representada por 56 estudiantes de la zona rural y urbana del municipio de Florencia Caquetá.

Palabras clave: conflicto armado; infancia; paz; estrategias lúdicas. 


\title{
Realities of the armed conflict in the actual contexts of childhood:
}

\section{A contribution to build peace from within the classroom}

\begin{abstract}
The objective of this article was to characterize the realities of the armed conflict that children have experienced in the department of Caquetá-Colombia. This study was based on the contributions of descriptive research with a qualitative approach. The main findings are related to the implementation of interviews, observation guides and field diaries. The results were consolidated through three phases: characterization, intervention and evaluation, taking as categories of analysis the social, cultural, psychosocial, cognitive and economic component. The population was represented by 56 students from the rural and urban areas of the municipality of Florencia Caquetá.
\end{abstract}

Keywords: armed conflict; childhood; peace; playful strategies

Artículo recibido: 10 Setiembre. 2021 Aceptado para publicación: 15 Octubre. 2021 Correspondencia: riquelio.vargas@unad.edu.co Conflictos de Interés: Ninguna que declarar 


\section{INTRODUCCIÓN}

Colombia es un país con una gran diversidad cultural, y riquezas naturales muy variadas; pero circunstancias de desigualdad de orden político, administrativo y social han generado división, concentración de riquezas en unos pocos y sectorización en la población al punto que han surgido grupos al margen de la ley y del orden público que se oponen a las formas amañadas de gobierno y protestan contra las acciones de inequidad, desigualdad y desprotección de derechos humanos que día tras día amplían la brecha entre ricos y pobres generando que la democracia sea cada vez más esquiva de alcanzar.

Márquez (2013) afirma que el conflicto armado surge cuando hay un confrontamiento entre diversos grupos con ideales diferentes. Esta guerra ha conllevado al deterioro del desarrollo integral de los niños, debido a los diferentes ambientes del conflicto armado en los que se han visto obligados a presenciar, estar inmersos y no poder vivir un ambiente de paz. Según el Instituto de Estudios Sobre Conflictos y acción Humanitaria (IECAH, 2010) la construcción de paz ésta relacionada con las acciones a corto, mediano y largo plazo, que le permiten a la escuela mediar los diferentes conflictos que ha dejado la guerra.

Por ello, la paz es el inicio de un cambio profundo, direccionado a mostrar el potencial de las presentes y futuras generaciones de Colombia. AFP (2013) menciona que los acuerdos de paz están apoyados por la mayoría de los colombianos, lo que indica un deseo profundo del éxito de la anhelada paz. En Colombia existen más de 5 millones de personas desplazadas a causa del conflicto interno, el $48 \%$ corresponde a menores de edad, que siguen viviendo en lugares urbanos donde existen diversos conflictos que afectan su desarrollo integral (Consejo Noruego para la Educación, 2014).

Cabe resaltar que los diálogos y acuerdos entre el Gobierno Nacional y las FARC para lograr la anhelada paz, van a permitir una mejor calidad educativa del país hacia la construcción de paz. El estudio realizado por Roa y Restrepo (2016) menciona que el 90\% de los estudiantes de Colombia expresan la importancia que en la escuela se inicie la formación para la construcción de paz. Santamaría (2015) señala que los acuerdos de paz han sido una oportunidad histórica para que Colombia reoriente sus esfuerzos y políticas en la resolución de los problemas reales que vive la niñez.

El conflicto interno que se ha vivido en el departamento de caqueta entre fuerza pública, grupos insurgentes y demás actores armados, impactó de manera directa las ifancias, 
deteriorando la estructura de muchas familias que fueron obligadas a salir de sus territorios de manera forzada y que en su mayoría, sufrieron la muerte de sus seres queridos sin razón alguna, tan solo por el hecho de habitar territorios en los cuales se daban enfrentamientos armados entre diversos grupos de forma permanente y/o habían sido considerados arbitrariamente por alguno de los actores armados, como zona exclusiva de operación.

Es importante reconocer que las realidades del conflicto armado que viviron los niños y sus familias, tambien se reflejó en un amento de la población desescolarizada en Colombia; niños, niñas, adolescentes y jóvenes que vivieron una condición de desplazamiento, donse se hacia visible la ausencia de motivación para acudir a las escuelas y colegios. Esto tambien se debe a que algunas familias pierdieron el interés en la educación por los múltiples problemas económicos y sociales que tienen que enfrentar, en los cuales consideran prioritario resolver temas economicos como trabajo, vivienda, alimentación (donde ven pertinente que los niños trabajen para ayudar a resolverlo) y por tanto la educación pasa a un segundo nivel de interés. Por ende, desde los alcances de este estdio se dio aportes a la educación para la paz, debido a que se convierte ahora, en el instrumento de cambio y transformación para superar las afectaciones que ha vivido la familia y en particular la niñez en Colombia (Hernández, 2016).

Los resultados de este artículo se estructuran a partir de las siguientes categorías de análisis: social, cultural, psicosocial, cognitivo y económico. Lo cual, permitió identificar como las realidades del conflicto armado impactan de forma directa las infancias, debido a que los niños que a temprana edad vivencian diversas situaciones de violencia se ven afectados en todas las áreas de su desarrollo integral (Ariel, 2012).

En este sentido, se partió de un estudio exploratorio para llegar a consolidar la utilización del tipo de investigación descriptiva con un enfoque cualitativo, que permitió analizar, comprender y explicar las realidades del conflicto armado en la vida de niños y cómo se manifiesta el impacto que causa en el desarrollo físico y biológico, socioafectivo, psicológico, emocional. Lo cual opaca la apropiación de habilidades sociales que permitan crecer en ambientes sanos y agradables para potenciar su desarrollo integral. Los resultados consisten en la identificación de características propias del conflicto armado que afectan la formación integral de las infancias. Las Instituciones en las cuales asiste la población estudiantil desde grado transición al grado undécimo son de carácter 
mixto y presentan condiciones socioeconómicas deficientes en cuanto a los recursos para para la garantía y vivencia de las categorías de derechos fundamentales de infancia (salud, vida, protección, participación

Los procesos educativos deben favorecer el desarrollo cognitivo de los niños afectados por el conflicto, donde se fortalezca la capacidad analítica y crítica, debido a que son las herramientas significativas para mediar el conflicto y las situaciones de post-acuerdo (Márquez, 2013). Muchos niños que están en su primera infancia aún están viviendo vacíos que les ha dejado el conflicto armado desde lo social, cultural, psicosocial, cognitivo y económico. La construcción de paz está relacionada con la cultura, entorno y el tiempo, por ello se requieren estrategias vitales para poder llevar a cabo el proceso (Núñez \& Haegraats, 2007).

En este sentido, a la escuela, la sociedad y la familia les compete empezar a mediar las huellas que ha dejado el conflicto armado en los niños. Aunque no es una tarea fácil, pero con diferentes ambientes de aprendizaje rodeados de estrategias pedagógicas, didácticas y psicológicas se emprenderá un camino donde los niños aprendan jugando y se potencie su desarrollo integral en espacios libres de conflicto. El Instituto en Primera Infancia y Derechos de la Niñez de la Organización de Estados Iberoamericanos (OEI, 2009) ha desarrollado diferentes estrategias de intervención a partir de procesos investigativos para aminorar las huellas que el conflicto armado ha dejado en los niños.

\section{ESTRATEGIAS METODOLÓGICAS O MATERIALES Y MÉTODOS}

El propósito de este estudio fue caracterizar las realidades del conflicto armado que han vivido los niños en el departamento del Caquetá- Colombia. Para ello, se incorporó el tipo de investigación descriptiva, buscando especificar las propiedades, las características y los perfiles importantes de personas, grupos, comunidades o cualquier otro fenómeno que se someta a un análisis (Hernández, Fernández y Baptista, 2014).

En correspondencia a lo anterior, se toma un enfoque de corte cualitativo, para analizar las causas y efectos que han causado el conflicto armado en los niños, y poder establecer estrategias que aporten a la solución del problema que están presentando los niños. Es importante analizar las experiencias y problemáticas que se presentan en una población desde el ámbito sociocultural y proponer estrategias para identificar el problema, buscar la solución y conocer el impacto causado mediante un proceso de experiencia en la práctica (Behar, 2008, p. 9). 
En este estudio, se tuvo en cuenta el sentir del niño, sus necesidades, expectativas e intereses como eje del proceso de enseñanza y aprendizaje; donde adquieren habilidades para una paz significativas basándose en los conocimientos previos en una lengua extranjera como el inglés. De acuerdo con Vygotsky (1935 citado en Vargas y Olaya 2017), los niños logran aprendizajes significativos a través de la interrelación con otros, donde está presente la zona de desarrollo próximo, que es el conocimiento previo, y el nivel de desarrollo potencial, que se logra a través de la colaboración e interacción con otros.

Por consiguiente, se diseñó un proceso de intervención basado en actividades lúdicas, en las cuales se integró el aprendizaje inglés. Según Vargas y Olaya (2017), el la lúdica permite un constante intercambio entre pares, las actividades están mediadas por el apoyo mutuo, el respeto por las ideas y turnos de habla. La intervención estuvo direccionada en brindar espacios de socialización, para que los estudiantes transformen y fundamenten de manera pertinente el concepto de paz, dejando poco a poco las huellas de la guerra. Por ello, es importante implementar las acciones establecidas en la Ley 1732 cátedra de la paz (2014), donde se propone crear y consolidar un espacio para el aprendizaje relacionado con el territorio, la cultura y el contexto para construir tejido social.

\section{De acuerdo a lo anterior, este estudio se llevó a cabo por medio de tres fases:}

Primeramente, se realizó una fase de caracterización, la cual, estuvo orientada en conocer las realidades del conflicto armado que han vivido los niños, así como sus gustos y anhelos sobre los temas de interés articulados con el inglés. Seguidamente, una segunda fase donde se llevó a cabo la intervención pedagógica; es decir, se diseñó y ejecutó el proyecto de aula para contribuir a la construcción de paz. Finalmente, una tercera fase de evaluación, con la cual se conoció el impacto del proyecto, para analizar y reflexionar sobre el proceso desarrollado. El grupo de niños objeto de estudio corresponde a 56 estudiantes; de ellos 26 niñas y 30 niños; viven en la zona urbana y rural de Florencia, sus edades oscilan entre los 6 y 8 años.

\section{RESULTADOS Y DISCUSIÓN}

Los resultados se enfocaron en las particularidades y los diferentes acontecimientos que niños y niñas han tenido que vivir dentro del conflicto armado. Este aspecto conlleva a reflexionar sobre la niñez en Colombia para empezar a construir acciones pedagógicas y ambientes de paz desde el aula de clase. La paz constructiva estimula estilos de vida 
prometedores para la sociedad, enfocados en la niñez (Blanco, 2014). De esta manera, los hallazgos obtenidos en la fase de caracterización y los resultados de la fase de intervención y evaluación, posibilitaron explorar y comprender las realidades en los contextos actuales de las infancias a partir de las percepciones y vivencias que han tenido los niños y niñas sobre el conflicto armado y paz. Se debe reconocer que la paz es la actividad conjunta y permanente en la que participa toda la sociedad, todos deben aportar en su construcción y sus bases se deben gestar desde las infancias (Santamaria, 2015).

En este sentido, se logró indagar y analizar las vivencias de conflicto que han tenido los niños y posteriormente se implementó un plan de acción con actividades para realizar un cambio y trasformar esas realidades en una base de construcción de paz, creando un tejido social desde edades tempranas, lo cual, ayuda a disminuir acciones de conflicto y violencia en la escuela. Es importante buscar que los niños que han vivido en el conflicto armado no guarden afectaciones de ese pasado, por el contrario, creen nuevas relaciones y formas de organización para apreciar la vida desde la posibilidad que la paz se construye (Ospina, Carmona y Alvarado p. 56, 2014).

De acuerdo a lo anterior, los procesos de enseñanza y aprendizaje, hacen un llamado a forjar la mirada en las infancias, para empezar a edificar una paz que perdure en la sociedad. Para Muñoz y Molina (2010), la paz trae ventajas en la sociedad debido a que se construye por medio de un proceso que puede ser sentida, conocida, pensada y percibida por los niños a temprana edad. Por consiguiente, se requiere de ambientes de aprendizaje agradables para la construcción de paz, donde haya participación activa de todos los agentes educativos, mediada por los valores, los derechos humanos y los deberes.

En este orden de ideas, el proyecto permite lograr grandes avances en la sociedad, donde se puedan resolver conflictos desde el diálogo y la valoración a la diversidad cultural. Cabe aclarar que, los aportes a la construcción de paz se construyen, se enseñan y se aprenden desde un proceso de entendimiento y práctica. De acuerdo con la Unicef (2006), la base para construir paz está en la infancia y se empieza con dar un buen trato a los demás, ser solidario, aceptar las diferencias, defender la vida y no hacer daño a los otros. Por ende, en este estudio se propuso transformar las realidades de conflicto armado que han vivido los niños y complementar el concepto de paz mediante actividades lúdicas que le permiten socializar e interactuar con otros para aprender a convivir. Este componente 
educativo es la base para empezar a construir paz desde el aula de clase mediante una inclusión activa de todos los niños que han sido afectados de manera directa e indirecta por el conflicto armado.

Por ello, este proyecto es de gran utilidad para la comunidad educativa, porque permite identificar aspectos del conflicto armado que conllevan al deterioro de la convivencia. Las actividades lúdicas se enfocaron en hacer visible la empatía, compañerismo, respeto y tolerancia, donde los estudiantes puedan comprender lo que significa vivir en paz y armonía. La paz sostenible depende de cada acto, como forma de sentir, vivir, actuar en y para la paz (Blanco 2014). Es importante potenciar la socialización en los niños, para que sean capaces de fortalecer la autoestima, puedan quererse a sí mismos y a los demás, este potencial afectivo le permite trasformar las afectaciones que les ha dejado el conflicto armado (Ospina et al., 2014).

De acuerdo con Buitrago, Cubillos, Ramírez y Tabares (2011), desde la escuela hay que motivar e involucrar a los niños a construir paz. Como lo menciona Carvajal (2015), "la educación es un camino para construir la anhelada paz y para recuperar la confianza en el otro, pues permite construir mejores ciudadanos comprometidos con la transformación social”. (p.75). La paz se empieza a construir en la infancia, para hacer las cosas de manera honesta y no llenar a la sociedad de odios y conflictos (Cifuentes, Rico, Casallas y Rodríguez, 2016).

Cuando se educa para la paz en edades tempranas, significa que la sociedad en el futuro contará con personas que van a transmitir y colocar en práctica lo adquirido en su infancia. La construcción de paz, está relacionada con una serie de estrategias orientadas a reducir los riesgos de recaer o decaer en un conflicto a parir del fortalecimiento de las capacidades de todos los estudiantes y empezar a sentar las bases de la paz (Fondo de naciones unidas para la construcción de la paz, 2014).

Es importante resaltar que la población más afectada por el conflicto armado en el Caquetá es la niñez, debido a que son más vulnerables y viven situación de marginalidad en la desintegración familiar que ha causado la guerra. Estas huellas perduran durante su vida, por ello, se requiere de apoyo a la infancia para empezar a "llenar - subsanarreparar" esos vacíos que ha dejado la guerra. Los niños que han sido víctimas de muertes de algún padre de familia, tío, hermano, padrino, entre otros. Barbero (2006), menciona que los diferentes conflictos armados en Colombia han llevado a generar crisis 
humanitaria y de afectación a los derechos humanos, no obstante, se hace clara referencia a las diferentes iniciativas locales, regionales, nacionales e internacionales para promover la paz.

Los niños que hacen parte de este proceso investigativo provienen de familias de zonas rurales y de corregimientos de diferentes municipios del departamento del Caquetá y por los efectos del conflicto armado emigraron a la ciudad de Florencia. La violencia del conflicto armado ha cambiado la vida de los niños, debido a que muchas familias se han desplazado de ambientes rurales a espacios urbanos engrosando los cordones de miseria y de extrema pobreza, donde inician a reconstruir sus vidas con grandes baches económicos (Grupo de Memoria Histórica 2013). Las familias de los niños que hacen parte de este estudio, se catalogan en condiciones económicas bajas, dependen de actividades laborales de oficios varios (moto-taxistas, vendedores ambulantes, pequeños comerciantes, auxiliares de servicios generales en hogares, entre otros).

Los resultados del proyecto surgen a partir de las realidades de conflicto armado que han vivido los estudiantes de grado primero de primaria. Se logró indagar a través de: una rejilla de socialización y relatos vividos por los niños, a partir del uso de las técnicas investigativas de observación directa y participante en el aula de clase y espacios que frecuentan los estudiantes dentro de la institución. Los integumentos implementados como la guía de observación y las entrevistas muestran que la socialización en espacios de juego y recreación, ha sido vulnerada a causa del miedo, la timidez, la desconfianza, el autoritarismo, el dominio de la fuerza, diversas formas de respuesta agresiva, entre otras afectaciones que les dejó las vivencias que tuvieron a causa de la guerra.

Muchas de las actividades lúdicas que realizaban los niños están relacionadas con vivencias de la guerra, jugaban a los soldados y la guerrilla, a los secuestrados, pandillas, el lenguaje usado por los niños en estos juegos tanto en palabras, gestos y acciones se considera réplica de las formas de comunicación propias de los actores del conflicto (fuerza pública - guerrilla - paramilitares) etc. Estas actividades de juegos dejan en evidencia que se ha afectado el desarrollo físico, social, afectivo, cognitivo y comportamental en la niñez. Bandura (1963 citado en Vargas y Olaya 2017), menciona que el aprendizaje social, está relacionado con aspectos de imitación de modelos que ocurren en su alrededor. 
En este sentido, es evidente que los niños que han sido víctimas del conflicto armado sienten timidez y miedo cuando se presentan conflictos en el aula de clase, esto hace que se aíslen constantemente de sus compañeros y sus procesos de socialización no son significativos en el aula de clase, porque se les dificulta establecer relaciones sociales. Anderson (2009), el conflicto armado ha impactado a la primera infancia, debido a la poca visibilidad que les han otorgado a los niños, esto ha dejado huellas en su desarrollo físico, social, afectivo, cognitivo y comportamental.

De igual manera, dentro de la variable de socialización se evidenció que otros niños que han sufrido las consecuencias de la guerra demuestran mayor agresividad a la hora de mediar los conflictos que se presentan en el aula de clase. Según la Defensoría del Pueblo (2002), menciona que las acciones de violencia que vivencia la niñez inciden en sus procesos de socialización, esto genera pérdida del sentido de valores de orden axiológico (respeto, valoración, capacidad de escucha, comprensión, rectitud, honradez, compasión), al mediar conflictos con los demás. Edificar la paz desde edades tempranas, es un llamado que compete a todos los agentes educativos, para resolver conflictos en el aula de clase sin acudir a la violencia, dando lugar a la movilización y vivencia de los derechos humanos.

Después de indagar las realidades del conflicto armado que han vivido los niños víctimas y conocer los conceptos de paz que han logrado interiorizar desde sus vivencias, se propusieron diferentes actividades lúdicas con énfasis en inglés por medio del proyecto de aula denominado "Conociendo los animales del bosque". Cuyo propósito fue mejorar los procesos de socialización y empezar a edificar una paz estable y duradera desde el aula de clase. De acuerdo con Baranyi (2006) la construcción de paz se basa en un estudio desde los orígenes del conflicto y la dinámica, para poder hacer de la paz una situación perdurable.

El proyecto se desarrolló durante 3 meses consecutivos del calendario escolar, por medio de secuencias didácticas a partir de actividades lúdicas para la construcción de paz. Ospina y Ospina (2017) mencionan que, en el conflicto armado colombiano, los niños y niñas han sido los sujetos más afectados por la violencia, pero también se han convertido en los agentes de cambio a partir del empoderamiento de sus derechos para la construcción de paz. La escuela en la construcción de paz debe proyectarse desde la convivencia para la resolución de conflictos de manera pacífica (Bedolla y Farfán, 2016). 
Es importante valorar la infancia como una etapa única y valiosa de cada niño. Por ello, se dan a conocer algunos relatos vividos por los niños en el conflicto armado y desde ahí empezar a ayudar a superar esos vacíos que ha dejado el conflicto armado y se empiece a construir paz desde el aula de clase. A continuación, se presentan algunos relatos:

- Estudiante 1: "cuando yo tenía 5 años vivía en La Novia, un corregimiento del municipio de Curillo del departamento del Caquetá, ubicado a orillas del río Fragua, mis padres eran propietarios de una droguería. Yo recuerdo que, en las noches y en los fines de semana, asesinaban a muchas personas; un domingo a la madrugada miramos por las rendijas de las tablas de mi casa, como asesinaban a mujeres y hombres. Estas personas eran arrastradas por las calles, y después eran arrojadas al río. Un día llegó un rumor que la guerrilla iba a asesinar a un farmaceuta. Y como mi padre era farmaceuta, nos llenamos de temor y nos alejamos de ese lugar".

- Estudiante 2: "les voy a contar cómo marcó mi vida la pérdida de mi perro Lucas. Con tan sólo 6 años, podría describir a mi perro como mi mejor amigo, me acompañaba y muchas veces jugábamos. Un día, mi tío se lo llevó a cazar y mi fiel amigo nunca regresó. Mi tío me contó que Lucas había muerto porque le había explotado una mina, ni siquiera pude enterrarlo, nunca más volví a ver a mi gran amigo. En mi recuerdo siempre vivirá y nunca lo podré reemplazar".

- Estudiante 3: "yo vivía en la finca y tenía un amiguito que vivía cerca, pasábamos muchos ratos de juegos. Un día pasó algo muy triste, mi amigo venia de a caballo para mi finca, pero no llegó, nosotros escuchamos que algo estalló muy fuerte. Entonces, mi mamá fue a la otra finca a preguntar qué había pasado. Mi mamá me contó que había estallado una mina, el caballo murió, pero mi amigo estaba vivo, pero un poco herido. Yo me sentía muy triste por él y sabía que no podríamos correr ni jugar en la planada por un largo tiempo. Después de eso y el miedo de otras cosas, nos vinimos a vivir a Florencia”.

Después de conocer los relatos vividos con los niños se denota que aspiran vivir felices en espacios libres de guerra donde puedan jugar con tranquilidad. La sociedad civil se ha convertido en una alidada en la paz, por su victimización y el anhelo para que sus presentes y futuras generaciones vivan en ambientes de paz (Rettberg, (2013).

En este sentido, con las actividades desarrolladas se denota un clima de armonía, el gusto y agrado por la vida de la escuela, los niños comprendieron que es un lugar tranquilo, 
libre de agresiones, de intimidaciones y alejado de todo tipo de violencia. El trabajo con los niños está relacionado con las construcciones simbólicas, que articula elementos resilientes, creativos y propositivos, que conllevan a cambiar los vacíos que ha dejado el conflicto armado por los juegos de la paz (Romero y Chávez, 2008).

Estas actividades, conllevaron a mejorar la socialización de los niños, aquellos que presentaban timidez y aislamiento dejaron a un lado esos vacíos y se fueron integrando poco a poco. Al finalizar las actividades se mostraron participativos, en algunas acciones de conflicto que se presentaron en las actividades colaborativas mostraron mayor disposición para solucionarlos. Echeverría (2005), afirma que la resolución de conflictos y la construcción de paz, influye en la capacidad para crear, trasformar y generar cambios pacíficos. De igual manera, los niños que jugaban con representaciones de guerra como a los soldados y la guerrilla, cambiaron esas manifestaciones de juego por actividades más apropiadas que se les enseñaron durante el desarrollo del proyecto. Los niños y las niñas aportan a la construcción en ambientes alejados de la violencia (Ospina y Ospina 2017).

\section{CONCLUSIÓN O CONSIDERACIONES FINALES}

Es importante resaltar el ser niño, donde se le reconozca como un ser único, desde sus características físicas, culturales y sociales. Diker (2009) menciona que los niños tienen características propias, el contexto influye en su formación, se refleja en las capacidades de pensar, actuar y relacionarse con los demás. En este estudio se pudo evidenciar que algunos niños víctimas de la guerra demuestran mayor agresividad a la hora de mediar los conflictos que se presentan en el aula de clase. Dentro de los estudios realizados por la Defensoría del Pueblo (2012), se encontró que las bajas habilidades de convivencia en los niños, surge por la pérdida de valores a causa del conflicto armado.

Los resultados permiten concluir que el conflicto armado en Colombia, ha traído consecuencias devastadoras para la niñez, como asesinatos, violaciones, secuestros, amputaciones, etc., esto ha generado destrucción en la sociedad afectando su desarrollo, ético, social, moral y comportamental. El odio, la falta de perdón y reparación, siguen presentes en la mayoría de las regiones de Colombia y se han trasmitido de generación en generación en estas cinco décadas de guerra. El conflicto armado ha generado desplazamiento de mujeres con sus hijos y a la desaparición, reclutamiento y asesinato de sus padres (Codhes, p. 13, 2008). 
Otra conclusión del estudio, es que los niños que han sido víctimas de la guerra, al presenciar conflictos en el aula de clase sienten timidez, miedos y se aíslan constantemente. Dentro del estudio se pudo denotar que el conflicto armado ha impactado a la primera infancia del Caquetá, se les ha otorgado poca visibilidad a los niños, afectando su desarrollo físico, social, afectivo, cognitivo y comportamental. Los niños representan nuevas posibilidades para empezar a dejar los odios y demás huellas del conflicto armado de Colombia y no repetir la historia violenta para garantizar la paz estable y duradera (Bernal, 2015)

Las actividades lúdicas desarrolladas permitieron mejorar la socialización de los niños, aquellos que presentaban agresividad en la resolución de conflictos, mostraron mayores habilidades y disposición para no acudir a las agresiones físicas y verbales. Los niños que presentaban timidez y aislamiento durante los conflictos empezaron a tomar iniciativas para ayudar a sus compañeros a mediar y solucionar aquellos desacuerdos que se generaban dentro y fuera del aula de clase. Al finalizar las actividades de intervención, se evidenció aprendizaje en inglés sobre los animales del bosque, también se observa un clima agradable entre los estudiantes. Los niños que habían sido víctimas del conflicto armado, reflejaban felicidad y armonía al llegar a la institución

\section{LISTA DE REFERENCIAS}

Baranyi, S. (2006). ¿Estabilización o paz sostenible? ¿Qué clase de paz es posible después del 11-S? [en línea]. Madrid: Centro de Investigación para la Paz (CIP-FUHEM). Disponible en: http://www.nsi-ins.ca/english/pdf/CONFLICTOS-11S. pdf.

Barbero A. (2006). Construyendo paz en medio de la guerra: Colombia. Cataluña, España.

Bedoya, E y Farfán, M. (2016). Reflexiones sobre la construcción de Representaciones Sociales que se construyen a cerca de Paz y Paces en los escenarios de reconciliación de las Comunidades Receptoras de Población en Proceso de Reintegración Social en los barrios Tokio y las Brisas de la Comuna Villa Santana en Pereira.

Bernal, E. C. (2015). El Tiempo: Infancia, un tema clave para el posconflicto. http://www.eltiempo.com/politica/proceso-de-paz/importancia-de-la-infanciaen-elposconflicto/16072455.

Blanco, J. E. (2014). Zona cero. Educación y posconflicto. Recuperado de 
Carvajal, C. (2015). La educación como horizonte para recuperar la confianza en un país herido por la violencia. Revista de la Universidad de La Salle, 66. pp. 75-82.

Chaux, E. (2012). Educación, convivencia y agresión escolar. Bogotá: Ediciones Uniandes. Taurus, Santillana.

Cifuentes, J, Rico, S. Casallas A y Rodriguez M. (2016). Jóvenes como sujetos sociales en construcción de paz en contextos escolares.

Codhes. (2011). ¿Consolidación de qué?, Informe sobre desplazamiento, conflicto armado y derechos humanos en Colombia 2010. Recuperado el Abril de 2011, de http://www.codhes.org/images/stories/pdf/bolet\%C3\%ADn\%2077.pdf

Congreso de la República de Colombia. (2014) Ley catedra de la paz. [Por el cual se reglamenta la ley 1732]. Bogotá, D.C., Colombia.

Consejo Noruego para la educación. (2014). Escuela, democracia y pos-acuerdo.

Daza, G. (2007). Lengua, guerra y paz. Revista Interacción, número 47. http://www.cedal.org.co/?s=h\&m=a

Defensoría del Pueblo (2002). La niñez en el conflicto armado colombiano. Bogotá: Unicef Colombia, Defensoría del Pueblo

Diker, G (2009). ¿Qué hay de nuevo en las nuevas infancias? Universidad Nacional de General Sarmiento. Buenos Aires : Biblioteca Nacional.

Fondo de Consolidación de la Paz de Naciones Unidas. (n.d.) ¿qué es Peacebuilding? Extraído 22 de enero de 2014. Desde: http://www.unpbf.org/applicationguidelines/what-is-peacebuilding/

Francisco Muñoz y Beatriz Molina, "Una cultura de paz compleja y conflictiva. La búsqueda de equilibrios dinámicos”, Revista Paz y Conflictos 3, (2010): 44-61.

Grupo de Memoria Histórica. (2013 )iBasta Ya! Colombia: Memorias de guerra y dignidad. Bogotá, Colombia: Imprenta Nacional.

Hernández R. (2014). Metodología de la investigación. Sexta edición. México D.F.

Hernández, E. (2016). Syllabus Electiva de línea “Educación para la paz”. Bogotá, Colombia: Universidad de La Salle.

http://www.eltiempo.com/politica/proceso-de-paz/posconflicto-en-colombia/15659117.

http://www.zonacero.info/opiniones/55320-educacion-y-posconflicto.

Iecah. (2014). Instituto de Estudios sobre Conflictos y Acción Humanitaria.(n.d). Construcción de la Paz. Extraído Enero 15, 2014. Desde 
http://www.iecah.org/web/index.php?option=com_content $\&$ view=article\&id=52 3 \&Itemid $=25$

Márquez, A. (2013). El papel de la educación en situaciones de posconflicto: estrategias y recomendaciones. Hallazgos, pp. 223-245.

Núñez J. \& Haegraats M. 2007. Diez años del Proceso de Barcelona: resultados y nuevos objetivos. Barcelona Centre for International Affairs CIDOB. En IV Seminario Internacional sobre Seguridad y Defensa en el Mediterráneo. Informes: Las armas de destrucción masiva en el Mediteráneo: estado de la cuestión y perspectivas (pág. 53). Barcelona, 2007.

OEI. (2009). Instituto en Primera Infancia y Derechos de la Niñez. Sede Colombia. Bogotá Colombia

Ospina et al. (2014). Niños en contexto de conflicto armado: Narrativas generativas de paz. Revista Infancia Imágenes, 13 (1), p 52-60. Colombia.

Ospina-Ramírez, D. A. \& Ospina-Alvarado, M. C. (2017). Futuros Posibles, el Potencial Creativo de Niñas y Niños para la Construcción de Paz. Revista Latinoamericana de Ciencias Sociales, Niñez y Juventud, 15(1), pp. 175-192.

Peñas, C. (2015). ¿Cómo podemos implementar la "cátedra de la paz" (MEN, 2015) en la educación preescolar? Revista Ruta Maestra, 13, pp. 82-91

Rettberg,A. (2013). La construcción de paz bajo la lupa: una revisión de la actividad y de la literatura académica internacional. Estudios Políticos, 42, Instituto de Estudios Políticos, Universidad de Antioquia, pp. 13-36.

Rico, E. (2009). El proyecto de aula una alternativa para el aprendizaje del inglés como segunda lengua en el English Support Centre del Colombo Hebreo. Licenciatura en lenguas modernas. Bogotá.

Roa, L. (2016). Violencia, paz y religión percepciones de los escolares de la media de Instituciones educativas de Manizales.

Romero, Y. y Chávez, Y. (2008). El juego de la guerra, niños, niñas y adolescentes en el conflicto armado en Colombia. Tabula Rasa (8), 197-210.

Vargas, R. y Olaya, H. (2017). Ambientes educativos de interacción para aprender colaborativamente en el grado primero de la Institución Educativa Cervantes sede Heliconias del Municipio de Morelia Caquetá. Universidad de la Amazonia. 